\section{Revista de CIENCIAS AMBIENTALES Tropical Journal of Environmental Sciences}

Revista de Ciencias Ambientales (Trop J Environ Sci). EISSN: 2215-3896.

(Enero-Junio, 2019) . Vol 53(1): 92-112.

Dol: http://dx.doi.org/10.15359/rca.53-1.5

Open Access: www.revistas.una.ac.cr/ambientales

EMAIL: revista.ambientales@una.ac.cr

Fournier M. L., Castillo L. E., Ramírez F., Moraga G., Ruepert C.

\title{
Evaluación preliminar del área agrícola y su influencia sobre la calidad del agua en el Golfo Dulce, Costa Rica
}

\author{
Preliminary Assessment of Agricultural Area and its Influence to the Quality of \\ Water in Golfo Dulce, Costa Rica
María Luisa Fournier ${ }^{1}$, Luisa E. Castillo ${ }^{2}$, Fernando Ramírez ${ }^{3}$, Geannina Moraga ${ }^{4}$, Clemens Ruepert $^{5}$

[Recibido: 28 de junio 2018, Aceptado: 16 de octubre 2018, Corregido: 13 de noviembre 2018, Publicado: 1 de enero 2019]

Nota: Resultados preliminares de este artículo fueron presentados en el I Congreso Centroamericano de Ciencias de la Tierra y el Mar, organizado por la Facultad de Ciencias de la Tierra y el Mar de la Universidad Nacional. 13-15 noviembre 2017, San José, Costa Rica.

\section{Resumen}

Se realizó una evaluación preliminar de la agricultura en las subcuencas Esquinas, Coto Colorado, Rincón, Conte, Agujas, Tigre y Palma, como criterio base para el diseño de un plan de seguimiento de la calidad del agua que ingresa al estuario. Se determinó el área de los cultivos, mediante interpretación de imágenes satelitales, para un total aproximado de 10000 ha de arroz Oryza sativa y 31000 ha de palma aceitera Elaeis guineensis. El uso de agroquímicos se estimó con base en información secundaria publicada y con encuestas administradas a grupos productores. El uso anual estimado de plaguicidas fue de $20.4 \mathrm{~kg} \mathrm{ha}^{-1} \mathrm{en}$ arroz y $6.6 \mathrm{~kg} \mathrm{ha}^{-1}$ en palma, y $840 \mathrm{~kg} \mathrm{ha}^{-1}$ $\mathrm{año}^{-1} \mathrm{de}$ fertilizantes granulados en ambos cultivos. Asimismo, se hizo un muestreo puntual de residuos de plaguicidas en agua, sedimento y peces, analizados con cromatografía de gases acoplada a espectrometría de masas y cromatografía de líquidos con detector de arreglo de diodos. En todas las muestras de agua se detectó el herbicida clomazone. Además, en la subcuenca Coto Colorado, la cual abarca el $95 \%$ del total del área agrícola que drena al golfo, se detectó el insecticida triazofos y los fungicidas isoprotiolano y propiconazol. La extensión y el manejo de las plantaciones agrícolas en la cuenca del Golfo Dulce, aunada a factores ambientales, podría representar una amenaza sobre los recursos del estuario. Por ello, se recomienda monitorear la calidad del agua en los ríos, así como iniciar programas de restauración de los bosques de ribera como medida de mitigación.

Palabras claves: Arroz; contaminación; cultivos; estuario; Golfo Dulce; palma aceitera.

1 Académica, Instituto Regional de Estudios en Sustancias Tóxicas, Universidad Nacional (UNA), Costa Rica; maria.fournier.leiva@una. ac.cr, ORCID: 0000-0002-0169-074X

2 Académica, Instituto Regional de Estudios en Sustancias Tóxicas, Universidad Nacional (UNA), Costa Rica, lecastillo2010@gmail.com, ORCID: 0000-0002-2641-6886

3 Académico, Instituto Regional de Estudios en Sustancias Tóxicas, Universidad Nacional (UNA), Costa Rica; fernando.ramirez.munoz@ una.ac.cr, ORCID: 0000-0003-0904-0204

4 Académica, Instituto Regional de Estudios en Sustancias Tóxicas, Universidad Nacional (UNA), Costa Rica; geannina.moraga.lopez@una. ac.cr, ORCID: 0000-0002-8221-8489

5 Académico, Instituto Regional de Estudios en Sustancias Tóxicas, Universidad Nacional (UNA), Costa Rica; clemens.ruepert@una.ac.cr, ORCID: 0000-0001-5109-2222

\begin{tabular}{|c|}
\hline 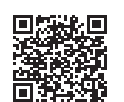 \\
\hline
\end{tabular}
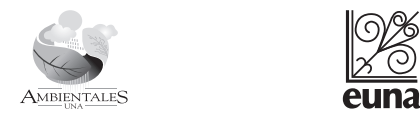


\section{Revista de CIENCIAS AMBIENTALES Tropical Journal of Environmental Sciences}

Revista de Ciencias Ambientales (Trop J Environ Sci). EISSN: 2215-3896.

(Enero-Junio, 2019) . Vol 53(1): 92-112.

DOl: http://dx.doi.org/10.15359/rca.53-1.5

Open Access: www.revistas.una.ac.cr/ambientales

EMAlL: revista.ambientales@una.ac.cr

Fournier M. L., Castillo L. E., Ramírez F., Moraga G., Ruepert C.

\begin{abstract}
With the purpose of designing a quality control program of the waters entering the estuary, a preliminary assessment of agricultural activity was done in the sub-basins Esquinas, Coto Colorado, Rincón, Conte, Agujas, Tigre, and Palma. The extension of the cultivated area was determined through interpretation of satellite images. With secondary information and surveys to producers, the use of pesticides and fertilizers was estimated. A point sampling was done for pesticide residues in water, sediment, and fish. The samples were analyzed with gas chromatography with mass detection and liquid chromatography with a diode array detector. An area of 10,000 ha of rice Oryza sativa and 31,000 ha of oil palm Elaeis guineensis plantations was estimated. Annual use of pesticides was estimated in $20.4 \mathrm{~kg} \mathrm{ha}^{-1}$ in rice and $6.6 \mathrm{~kg} \mathrm{ha}^{-1}$ in oil palm, and $840 \mathrm{~kg} \mathrm{ha}^{-1} \mathrm{yr}^{-1}$ of granulated fertilizers in both crops. The herbicide clomazone was detected in all water samples. Furthermore, in the Coto Colorado sub-basin, which encompasses $95 \%$ of the total agricultural area that drains into the gulf, the insecticide triazophos and fungicides isoprothiolane and propiconazole were also detected. The extension and management of agricultural plantations in the watershed that drains into the Golfo Dulce, in addition to its environmental factors, could pose a threat to the estuary resources. It is advisable to monitor the quality of water in rivers, as well as to develop programs for the restoration of the riparian forests as a mitigation measure.
\end{abstract}

Keywords: Estuary; crops, Golfo Dulce; pollution; rice, oil palm.

\title{
1. Introducción
}

El Golfo Dulce es una bahía semicerrada de formación tectónica y un sitio de alta diversidad biológica. Se localiza en la costa meridional de la provincia de Puntarenas, en aguas del océano

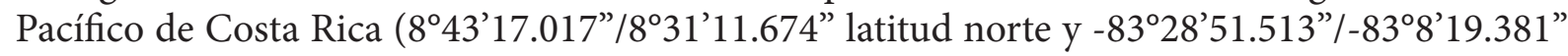
longitud oeste). La cuenca interna tiene una profundidad máxima de $215 \mathrm{~m}$ y la externa de $70 \mathrm{~m}$ promedio, con $40 \mathrm{~m}$ de profundidad a la entrada, lo que restringe la circulación y hace más lenta la renovación del agua en las partes profundas (Wolff et al., 1996). El golfo tiene un área de 750 $\mathrm{km}^{2}$ con $50 \mathrm{~km}$ de longitud y de 10 a $15 \mathrm{~km}$ de ancho; en sus aguas se encuentran el $21.5 \%$ de las 4745 especies registradas para la costa del Pacífico de Costa Rica (Morales-Ramírez, 2011). Sin considerar isla del Caño, el Golfo Dulce cuenta con el área de arrecife coralino más grande de la costa del Pacífico (Cortés, 1992).

Estos ecosistemas marino costeros así como los dulceacuícolas y fluviales están expuestos a impactos negativos por el arrastre de sustancias tóxicas, fertilizantes y a cambios hidrológicos debidos a la agricultura (Howarth, 2008; Moss, 2008). El uso de plaguicidas agrícolas en Costa Rica es alto y se ha triplicado en relación con la década de 1980. Según Ramírez et al. (2014), para el año 2012 se estimó un uso anual de $19.6 \mathrm{~kg}$ de ingrediente activo (i.a.) por hectárea cultivada. Esto aumenta el riesgo de contaminación difusa sobre los cuerpos de agua y otros compartimentos ambientales como aire, biota y suelos.

Las sustancias químicas peligrosas, cuando entran en aguas superficiales por deriva y escorrentía, pueden generar efectos a corto o a largo plazo en las poblaciones de peces y otros organismos acuáticos, según sea su concentración y toxicidad (Beketov et al., 2013). Varios estudios realizados en otras regiones del país han informado sobre la presencia de residuos de plaguicidas

\begin{tabular}{|c|c|c|}
\hline 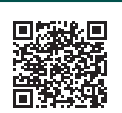 & (c) (i) () () () & 93 \\
\hline
\end{tabular}




\section{Revista de CIENCIAS AMBIENTALES Tropical Journal of Environmental Sciences}

Revista de Ciencias Ambientales (Trop J Environ Sci). EISSN: 2215-3896.

(Enero-Junio, 2019) . Vol 53(1): 92-112.

Dol: http://dx.doi.org/10.15359/rca.53-1.5

Open Access: www.revistas.una.ac.cr/ambientales

EMAlL: revista.ambientales@una.ac.c

Fournier M. L., Castillo L. E., Ramírez F., Moraga G., Ruepert C.

y sus efectos negativos sobre la biodiversidad de los ecosistemas acuáticos (Echeverría-Sáenz et al., 2012; Fournier et al., 2018; Mena et al. 2014). A pesar de la riqueza marina del Golfo Dulce, no se han desarrollado estudios sobre la agricultura en las subcuencas, ni la ocurrencia de plaguicidas de uso actual en los ríos y su posible influencia en el ecosistema estuarino.

Por no contar con información sobre la actividad agrícola en la cuenca del Golfo Dulce, se planteó esta evaluación inicial. En este estudio se identificó y midió la extensión de los cultivos más importantes dentro del área de drenaje al Golfo Dulce, mediante interpretación en un ambiente SIG; también se estimó con información secundaria y de campo el uso de plaguicidas y fertilizantes. Además, se hizo un muestreo preliminar, en los meses de junio y julio de 2014, en las bocas de los ríos para determinar la presencia de residuos de plaguicidas en agua, sedimento y peces, y el contenido de mercurio total en músculo de peces; estos resultados servirán de base para el diseño de un plan de seguimiento de la calidad del agua que ingresa al estuario.

\section{Materiales y métodos}

\section{1 Área de estudio}

El área de estudio, 218603 ha, en donde se analizó el uso de la tierra, comprende las subcuencas de los ríos Esquinas, Coto Colorado, Rincón, Conte, Agujas, Tigre y quebrada Palma. Durante el año 2014, se realizó un estudio del uso de la tierra mediante interpretación de imágenes de satélite y se realizaron 4 giras de campo: en abril se encuestó el uso de plaguicidas en los cultivos de palma y arroz; en junio y julio se recolectaron las muestras ambientales, y en diciembre se realizó la corroboración en terreno del uso de la tierra.

\subsection{Uso de la tierra}

La cobertura de uso de la tierra se obtuvo mediante la interpretación de imágenes de satélite RapidEye del año 2012 a escala 1:25 000. Según el objetivo del trabajo y el conocimiento a priori del área de estudio, esto se estructuró en cuatro niveles (protegido, tierra agropecuaria, cobertura boscosa, otro) y con siete clasificadores de uso (área protegida, pasto, arroz, palma africana, cobertura boscosa, manglar, cuerpo de agua, zona antrópica y sin información). El método de clasificación fue manual; se excluyó el área correspondiente al mapa de áreas silvestres protegidas del Sistema Nacional de Áreas de Conservación (SINAC, 2008), lo que restó 34561,8 ha del área total a interpretar y clasificar. Con base en patrones de tamaño, sombra, forma y tono (Lindgren, 1985), se obtuvo el mapa final, con el uso del software ArcGIS (Versión 10.3, ESRI). Al utilizar un método manual de clasificación se definió una validación en campo, con un nivel de confianza de $98 \%$; resultó en un tamaño muestral de $n_{0}=135.25$ dado por la Ecuación 1 (Araya-Alpízar y Galindo-Villardon, 2009).

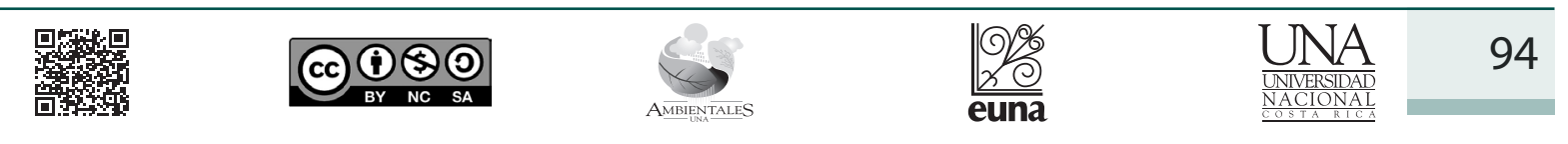




$$
n_{0}=\frac{Z^{2} p * q}{d^{2}}
$$

Donde:

Z: nivel de confianza $\left(98 \%=Z_{\alpha} 2.326\right)$

$\mathrm{p}$ : varianza de la proporción $(0.5)$

$\mathrm{q}$ : varianza de la proporción $(1-\mathrm{p}=0.5)$

d: error de estimación $(10 \%=0.10)$.

Para validar la cobertura de uso de la tierra, se obtuvo un listado de 135 puntos a partir del algoritmo que crea puntos aleatorios, a verificar en campo. De acuerdo con desarrolladores del software (ESRI), los puntos aleatorios se pueden generar en una extensión territorial específica, en este caso dentro de entidades poligonales, dadas por el límite del área de estudio. Además, la validación fue priorizada en los polígonos de uso agrícola, específicamente las áreas de pastos, y las siembras de palma aceitera y arroz, ambos cultivos seleccionados para el diagnóstico de uso de plaguicidas.

\subsection{Uso de agroquímicos}

Con el fin de estimar la carga total anual de agroquímicos aplicados en los cultivos agrícolas extensivos en la cuenca del Golfo Dulce, dado que no hay información disponible en las cámaras de productores ni datos del Servicio Fitosanitario del Estado, se utilizó información de campo y publicada (Ramírez et al., 2017). El uso de plaguicidas y fertilizantes en el cultivo de palma aceitera se basó en Ramírez et al. (2017), en entrevistas del periodo 2012-2013 a 14 personas encargadas de plantaciones y productoras asociadas en el Pacífico central y sur, pertenecientes a las organizaciones Coopeagropal y Palma Tica en las localidades de Coto 47, Quepos y Palmar.

En el caso de las plantaciones de arroz, se aplicó una encuesta sobre uso de agroquímicos a grupos agricultores del área de estudio, correspondiente al año arrocero 2013-2014. Se entrevistaron 7 personas productoras con un área total sembrada de 223 ha; se indagó sobre el área de cultivo en cada ciclo y su producción, el nombre y formulación de los plaguicidas y fertilizantes usados en cada etapa de cultivo, desde el vivero hasta el manejo postcosecha, dosis utilizada, frecuencia, descarga y equipo de aplicación, entre otros. Se calculó el uso ponderado promedio para cada uno de los plaguicidas utilizados en los cultivos de palma aceitera y arroz, y el resultado se expresó en kg i.a. ha ${ }^{-1}$ año $^{-1}$.

\subsection{Muestras ambientales}

En la evaluación preliminar de contaminantes agrícolas en los distintos compartimentos ambientales, se seleccionaron, por su accesibilidad, 8 puntos para muestrear agua y sedimento en las bocas de los ríos. Los peces se recolectaron en zonas cercanas a las desembocaduras. Los puntos de muestreo son quebrada Palma (S1) y ríos Rincón (S2), Conte (S3), Agujas (S4) y Tigre (S5) en la península de Osa (margen occidental del golfo); el río Coto (S6) a la altura

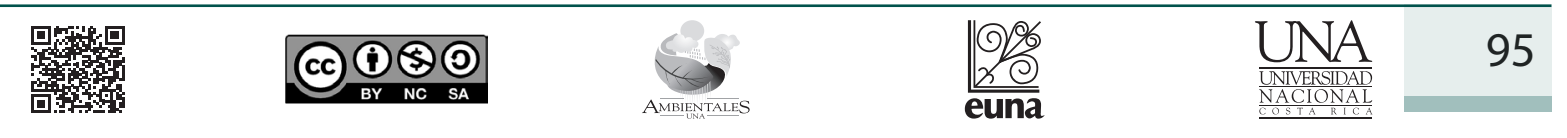




\section{Revista de CIENCIAS AMBIENTALES Tropical Journal of Environmental Sciences}

Revista de Ciencias Ambientales (Trop J Environ Sci). EISSN: 2215-3896. (Enero-Junio, 2019) . Vol 53(1): 92-112. Dol: http://dx.doi.org/10.15359/rca.53-1.5 Open Access: www.revistas.una.ac.cr/ambientales EMAIL: revista.ambientales@una.ac.cr

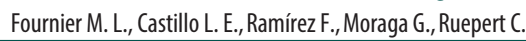

del puente en la ruta entre Golfito y Zancudo, y el río Sábalo en 2 sitios: La Virgen (S7) y en la boca (S8). Los últimos 3 puntos están localizados al sureste del Golfo Dulce y pertenecen a la subcuenca Coto Colorado (Figura 1); los puntos S6 y S7 no están en el área costera. Las muestras de agua, sedimento y peces se recolectaron en una sola ocasión, entre los meses de junio y julio de 2014. Todas las muestras se mantuvieron en una hielera entre 4 y $6{ }^{\circ} \mathrm{C}$ por un periodo no mayor a $48 \mathrm{~h}$ antes de su entrega al laboratorio.

De forma in situ, se midieron los parámetros fisicoquímicos de temperatura, $\mathrm{pH}$, conductividad y salinidad en el agua superficial de los puntos de muestreo con un equipo HACH HQ $40 \mathrm{D}$ con varias sondas. Las muestras de agua fueron recolectadas de forma puntual a $0.2 \mathrm{~m}$ de la superficie, en frascos de polipropileno de $0.5 \mathrm{~L}$ para los parámetros físico-químicos y nutrientes, y en 2 botellas de vidrio pre lavadas de $1 \mathrm{~L}$ para residuos de plaguicidas. En las muestras de agua se determinaron los sólidos disueltos totales y suspendidos, y las concentraciones de nutrientes (nitrato, fósforo total, fósforo libre) según los métodos estándar APHA (2005).

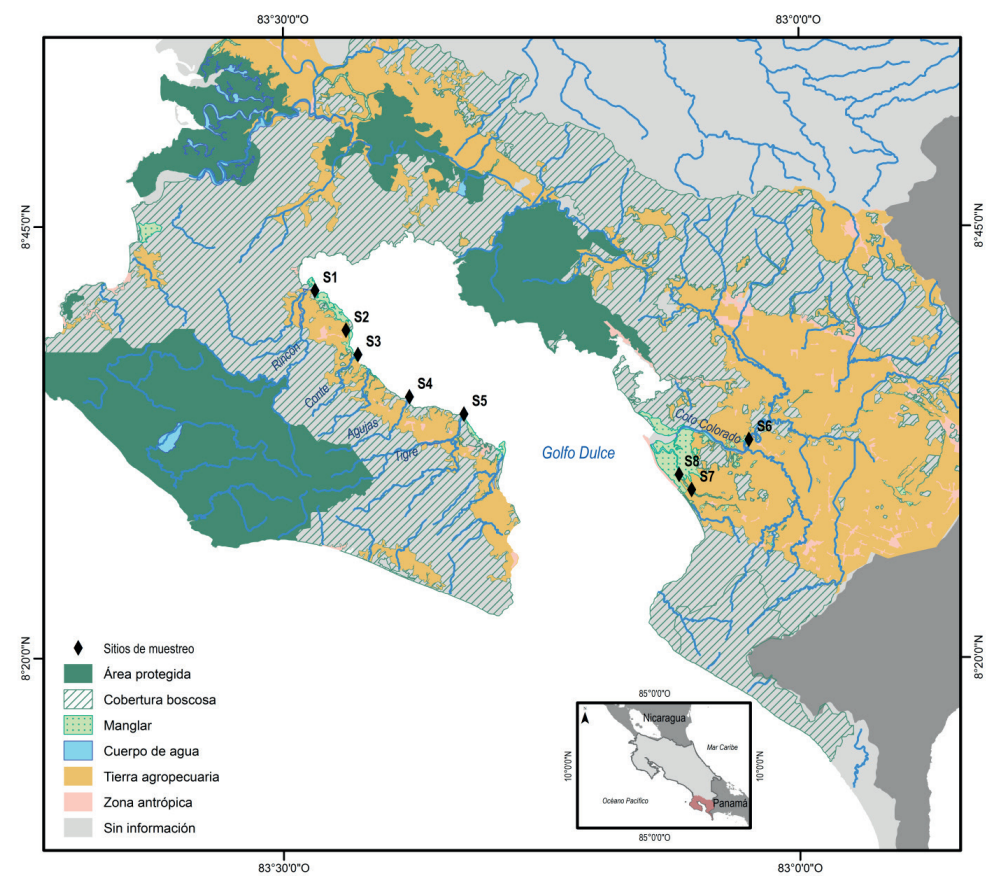

Figura 1. Uso de la tierra en la zona de estudio y sitios de muestreo en los ríos que drenan al Golfo Dulce; 2012.

Para los análisis de residuos de plaguicidas en las muestras de agua sin filtrar, cada botella de $1 \mathrm{~L}$ se extrajo por aparte, mediante extracción en fase sólida utilizando cartuchos Isolute Env + $200 \mathrm{mg}, 6 \mathrm{~mL}$ (Biotage, Suecia). Estos fueron previamente acondicionados con metanol y agua ultra pura, y eluidos con 3 x $3 \mathrm{~mL}$ de acetato de etilo o de metanol, dependiendo de la técnica de análisis instrumental, y concentrados con un flujo de nitrógeno a $1 \mathrm{~mL}$. Los plaguicidas no

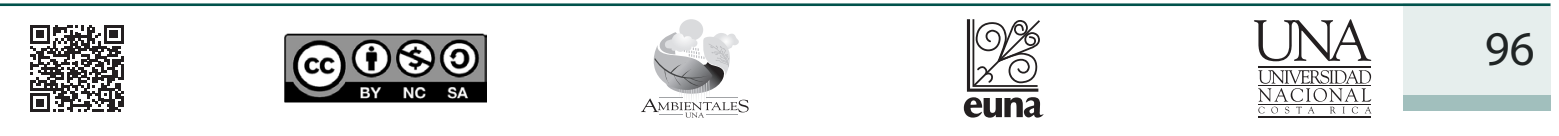




\section{Revista de CIENCIAS AMBIENTALES Tropical Journal of Environmental Sciences}

Revista de Ciencias Ambientales (Trop J Environ Sci). ElSSN: 2215-3896.

(Enero-Junio, 2019) . Vol 53(1): 92-112.

Dol: http://dx.doi.org/10.15359/rca.53-1.5

Open Access: www.revistas.una.ac.cr/ambientales

EMAIL: revista.ambientales@una.ac.c

Fournier M. L., Castillo L. E., Ramírez F., Moraga G., Ruepert C.

polares se identificaron y cuantificaron mediante el método de cromatografía de gases acoplado a espectrometría de masas (GCMS, por sus siglas en inglés) en modo de escaneo total (TIC) y de monitoreo selectivo de iones (SIM); y para plaguicidas polares, por cromatografía de líquidos con detector de arreglo de diodos (LC-PDA, por sus siglas en inglés).

En el análisis por cromatografía de gases se utilizó un equipo marca Agilent 7890A GC y 5975C MS (Agilent Technologies, Palo Alto, EEUU), en sincronía SIM y modo de escaneo, con un automuestrador (CTC Analytics AG, Suiza) y una columna capilar BPX35 de $25 \mathrm{~m} \times 0.25$ $\mathrm{mm} \times 0.25 \mu \mathrm{m}$ (SGE, EEUU). Para la obtención de datos se utilizó el software Chemstation y NIST08 Mass Spectral Database. La temperatura programada fue de $90^{\circ} \mathrm{C}(1 \mathrm{~min})$ a $210^{\circ} \mathrm{C}(20$ ${ }^{\circ} \mathrm{C} / \mathrm{min}$ ) y luego hasta $300{ }^{\circ} \mathrm{C}\left(4^{\circ} \mathrm{C} / \mathrm{min}\right)$; la interfase se sostuvo a $280^{\circ} \mathrm{C}$, la fuente de iones y el inyector a $230^{\circ} \mathrm{C}$. Las muestras $(2 \mu \mathrm{L})$ se inyectaron en modo splitless. Los plaguicidas incluidos en el análisis se identificaron usando tiempo de retención, espectro de masas y la razón entre los tres iones escogidos para cada plaguicida en modo selectivo. Los plaguicidas detectados se cuantificaron mediante calibración externa, y se inyectaron patrones de plaguicidas. Para la verificación de la eficiencia de extracción se aplicó etion como estándar interno, por su estabilidad química y tratarse de un plaguicida organofosforado no utilizado en el país.

Para los análisis en LC-PDA (por sus siglas en inglés) se usó un equipo marca Shimadzu HPLC LC-10AD con SPD-M10A como detector arreglo de diodos (Shimadzu, Kyoto, Japón). Se utilizó la columna de cromatografía LichroCART HPLC RP - 18 e columna de $125 \mathrm{~mm} \times$ $3 \mathrm{~mm}$ con $5-\mu \mathrm{m}$ (Merck, Alemania) mantenida a $40^{\circ} \mathrm{C}$. La fase móvil consistió en $20 \mathrm{mM}$ de acetato de sodio en agua ultra pura/metanol $56: 44 \mathrm{~V} / \mathrm{V}$ (solvente A) y metanol (solvente B); con un flujo de $0.5 \mathrm{~mL} / \mathrm{min}$. El programa de la gradiente de elusión inició con $100 \%$ del solvente A, luego bajó a $50 \%$ en 15 min y se mantuvo por 5 min, a $20 \%$ en 5 min y se mantuvo por 5 min, por último se aumentó a $100 \%$ en 5 min y se sostuvo por 5 min para una corrida total de $45 \mathrm{~min}$. El volumen de inyección fue de $50 \mu \mathrm{L}$. La identificación de los plaguicidas incluidos en el análisis se realizó usando tiempo de retención y espectro UV, y la cuantificación por calibración externa. En el análisis por ambas técnicas se incluyó en total un listado de más de 60 plaguicidas utilizados, entre otros, en cultivos de arroz y palma aceitera, con una recuperación de los plaguicidas analizados entre 70 y $120 \%$, y para la mayoría de los compuestos con límites de cuantificación entre 0.02 y $0.05 \mu \mathrm{g} / \mathrm{L}$.

En un recipiente plástico de $500 \mathrm{~mL}$ se recolectó manualmente y con una espátula metálica grande, una muestra compuesta de sedimento de la capa superficial del fondo de la orilla de cada una de las bocas accesibles de los ríos Rincón, Tigre y Conte. Los sedimentos fueron guardados en el laboratorio a $-20^{\circ} \mathrm{C}$ hasta su extracción. Cada muestra de sedimento fue homogenizada, y después se tomó en duplicado $2 \mathrm{~g}$ para extracción asistida en microondas (Mars 5, CEM, Corporation Matthews, NC, EEUU) con $20 \mathrm{~mL}$ de acetona/hexano (1:1) (EPA, 2007a), seguido de un análisis con cromatografía de gases con detector de masas con las mismas condiciones de las muestras de agua.

\begin{tabular}{|c|c|c|c|c|c|}
\hline 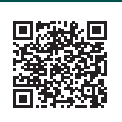 & (c) (1) () (2) & $\Leftrightarrow$ & 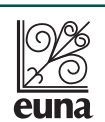 & 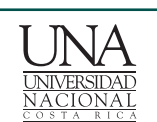 & 97 \\
\hline
\end{tabular}




\section{Revista de CIENCIAS AMBIENTALES Tropical Journal of Environmental Sciences}

Revista de Ciencias Ambientales (Trop J Environ Sci). EISSN: 2215-3896. (Enero-Junio, 2019) . Vol 53(1): 92-112. Dol: http://dx.doi.org/10.15359/rca.53-1.5 Open Access: www.revistas.una.ac.cr/ambientales EMAIL: revista.ambientales@una.ac.cr

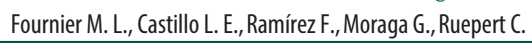

Además, cerca de las desembocaduras de los ríos se recolectaron con atarraya, 10 especies de peces (un individuo por especie) en colaboración con grupos pescadores locales; cada pez se envolvió en papel de aluminio prelavado y se etiquetó. En el laboratorio, se midió la longitud estándar $(\mathrm{cm})$ o la medida desde la cabeza hasta el punto medio de inicio de la aleta caudal y el peso total (g) de los peces, y se tomaron porciones de músculo para los análisis. Para la determinación de plaguicidas clorados persistentes en peces, se tomó $5 \mathrm{~g}$ de peso húmedo de muestra de músculo, de la que se extrajeron los lípidos según Smedes (1999). Para esto se homogenizó la muestra en un tubo de centrifugación, con una mezcla de isopropanol y ciclohexano por medio de un Ultraturrax T25 (IKA, Alemania) durante 2 minutos; después se agregó agua y se homogenizó de nuevo y se separó la fase orgánica por centrifugación. Luego de una segunda extracción con isopropanol/ciclohexano, se juntaron las dos fases orgánicas, se agregó sulfato de sodio y por último, se concentró la fase orgánica con rotavapor, se transvasó y se concentró a sequedad con un flujo de nitrógeno para la determinación de la cantidad de lípidos. Los lípidos se disolvieron en $\mathrm{n}$-hexano a una concentración no mayor de $100 \mathrm{mg} / \mathrm{mL}$. Se aplicó una limpieza del extracto con ácido sulfúrico concentrado, se agregó el ácido en la misma proporción que el hexano. De seguido, se separó la fase orgánica por centrifugación y se extrajo una vez más el ácido sulfúrico con $3 \mathrm{~mL}$ de hexano. Las fases orgánicas se juntaron y se concentraron al final con nitrógeno a $1 \mathrm{~mL}$. En los extractos se determinaron a-HCH, aldrin, clordano, heptacloro, $\mathrm{p}, \mathrm{p}^{\prime}-\mathrm{DDD}$ y $\mathrm{p}, \mathrm{p}^{\prime}-\mathrm{DDE}$ con cromatografía de gases con detector de masas en modo selectivo y modo escaneo total, aplicando las mismas condiciones antes mencionadas y con límites de detección y cuantificación de 0.1 y $0.5 \mu \mathrm{g} / \mathrm{g}$ de lípidos, respectivamente. Para verificar la eficiencia de la extracción, se agregó al inicio de esta misma un estándar interno marcado de p,p'-DDE $\left({ }^{13} \mathrm{C} 12 \mathrm{p}, \mathrm{p}^{\prime}-\mathrm{DDE}\right)$.

Las mediciones de mercurio total (Hg-T) en las muestras de biota se realizaron en la Universidad de Manitoba, Winnipeg, Canadá. En el laboratorio de Ecotoxicología del IRET, se tomó una sección de músculo de alrededor $5 \mathrm{~g}$ debajo de la aleta dorsal del pez, se eliminó el tejido cutáneo y se congeló a $-20^{\circ} \mathrm{C}$ hasta el envío en frío a Canadá para su análisis. Las herramientas se limpiaron entre cada disección. Una porción de $0.1 \mathrm{~g}$ de tejido húmedo se colocó en un vial para muestra y mediante un inyector automático se introdujo en un analizador directo de mercurio (Hydra IIc, Teledyne Leeman Labs). La muestra se descompone térmicamente a 800 ${ }^{\circ} \mathrm{C}$, el mercurio se concentra mediante amalgamación de oro y se detecta por espectroscopía de absorción atómica de vapor frío, el límite de detección fue de $5 \mathrm{ng} / \mathrm{g}$. Para el control de calidad se utilizó proteína de pescado como material de referencia (DORT-3), certificado por el Consejo Nacional de Investigaciones de Canadá; la recuperación fue de $107 \pm 1.4 \%(\mathrm{n}=4)$.

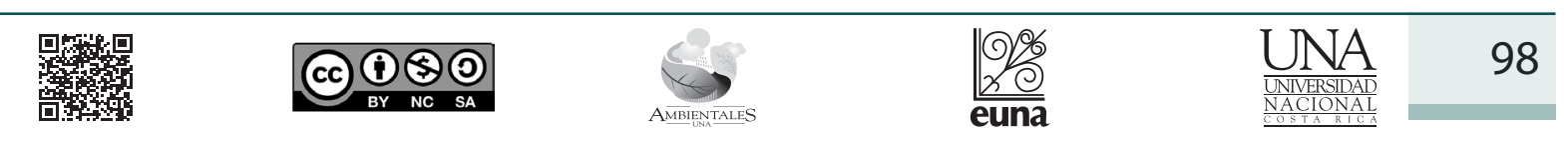




\section{Revista de CIENCIAS AMBIENTALES Tropical Journal of Environmental Sciences}

Revista de Ciencias Ambientales (Trop J Environ Sci). EISSN: 2215-3896. (Enero-Junio, 2019) . Vol 53(1): 92-112. Dol: http://dx.doi.org/10.15359/rca.53-1.5 Open Access: www.revistas.una.ac.cr/ambientales EMAlL: revista.ambientales@una.ac.cr Fournier M. L., Castillo L. E., Ramírez F., Moraga G., Ruepert C.

\section{Resultados}

\section{1 Áreas de cultivo y conservación}

Con base en la interpretación de imágenes de satélite, se determinó que al Golfo Dulce drenan 7 cuencas con 41444 ha de cultivos: 9931 ha de arroz, 30754 ha de palma aceitera y 759 de otros cultivos pequeños (Cuadro 1). E1 $95 \%$ del área total de ambos cultivos se encuentra en la subcuenca Coto Colorado, así como el $78 \%$ del área total de manglar. Cerca de la mitad del área de esta subcuenca (69 183 ha) corresponde al área boscosa de la Reserva Indígena Conte Burica y 68 ha son parte del área protegida del Refugio de Vida Silvestre (RVS) Golfito. Casi toda la subcuenca Esquinas está cubierta de bosque, más de la mitad integra el Parque Nacional (PN) Piedras Blancas y el RVS Golfito, en la margen nororiental de la parte interna del golfo (Figura 2); al igual que en las otras subcuencas, no toda el área de bosque está protegida con alguna categoría de manejo.

Cuadro 1. Uso de la tierra en las subcuencas de Golfo Dulce, en hectáreas; 2012

\begin{tabular}{lccccccc}
\hline & Esquinas & Coto Colorado & Palma & Rincón & Conte & Agujas & Tigre \\
\hline Área protegida & 16903 & 68 & - & 5634 & - & 586 & 2606 \\
Cobertura boscosa & 13782 & 68845 & 19 & 15350 & 1861 & 1598 & 7798 \\
Manglar & - & 2093 & 0.1 & 480 & 12 & - & 13 \\
Centro poblado & 197 & 4960 & 2 & 114 & - & - & 27 \\
Cuerpo de agua & - & 790 & - & 61 & - & - & 62 \\
Arroz & - & 8896 & 73 & 895 & 67 & - & - \\
Palma aceitera & 575 & 29449 & 66 & 273 & 26 & 106 & 259 \\
Pasto & 1822 & 23249 & - & 1003 & 312 & 100 & 444 \\
Otros cultivos & 99 & 660 & - & - & - & - & - \\
Sin dato* & 433 & 5933 & - & - & - & - & - \\
Total & $\mathbf{3 3 8 1 1}$ & $\mathbf{1 4 4 9 4 3}$ & $\mathbf{1 6 0}$ & $\mathbf{2 3 8 1 0}$ & $\mathbf{2 2 7 8}$ & $\mathbf{2 3 9 0}$ & $\mathbf{1 1 2 0 9}$ \\
\hline
\end{tabular}

"Vacíos de la imagen o nubes.

Así mismo, el $64 \%$ del área total en Rincón y el $23 \%$ en Tigre está cubierto por bosque, localizado en las secciones altas de las subcuencas. En ambas, alrededor de $35 \%$ del bosque es parte del PN Corcovado. En ese sector del golfo, las zonas agrícolas están en las partes bajas cercanas a la costa (Figura 3). La mayor área de arroz en la margen occidental se encuentra en la subcuenca Rincón (895 ha), seguida por quebrada Palma (73 ha) y Conte (67 ha). En todas las subcuencas de esta margen se cultiva palma aceitera, para un total de 730 ha.

\begin{tabular}{|c|c|c|}
\hline 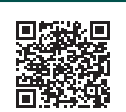 & (c) (i) (5) () & 99 \\
\hline
\end{tabular}




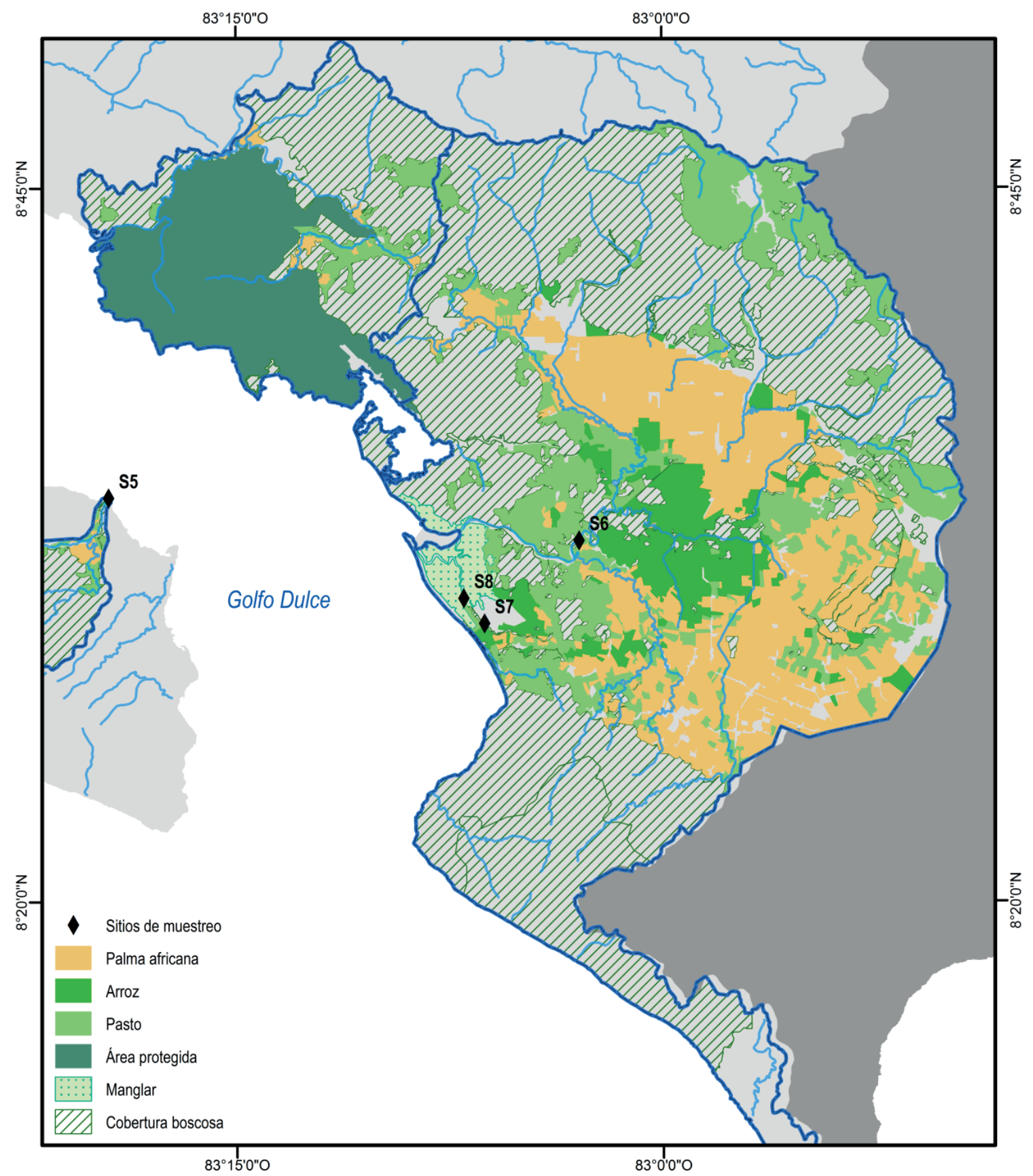

Figura 2. Área de cultivos agrícolas en las subcuencas Esquinas y Coto-Colorado, Golfo Dulce; 2012.

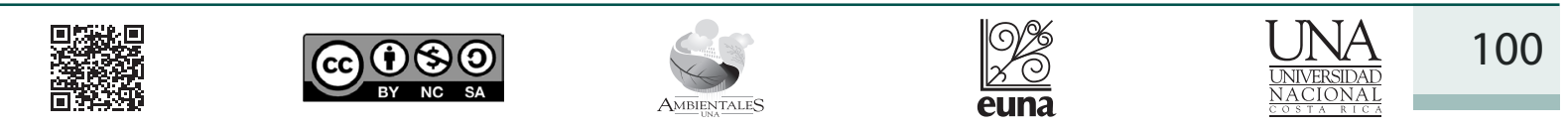




\section{Revista de CIENCIAS AMBIENTALES Tropical Journal of Environmental Sciences}

Revista de Ciencias Ambientales (Trop J Environ Sci). EISSN: 2215-3896. (Enero-Junio, 2019) . Vol 53(1): 92-112. D0l: http://dx.doi.org/10.15359/rca.53-1.5 Open Access: www.revistas.una.ac.cr/ambientales EMAlL: revista.ambientales@una.ac.c Fournier M. L., Castillo L. E., Ramírez F., Moraga G., Ruepert C.

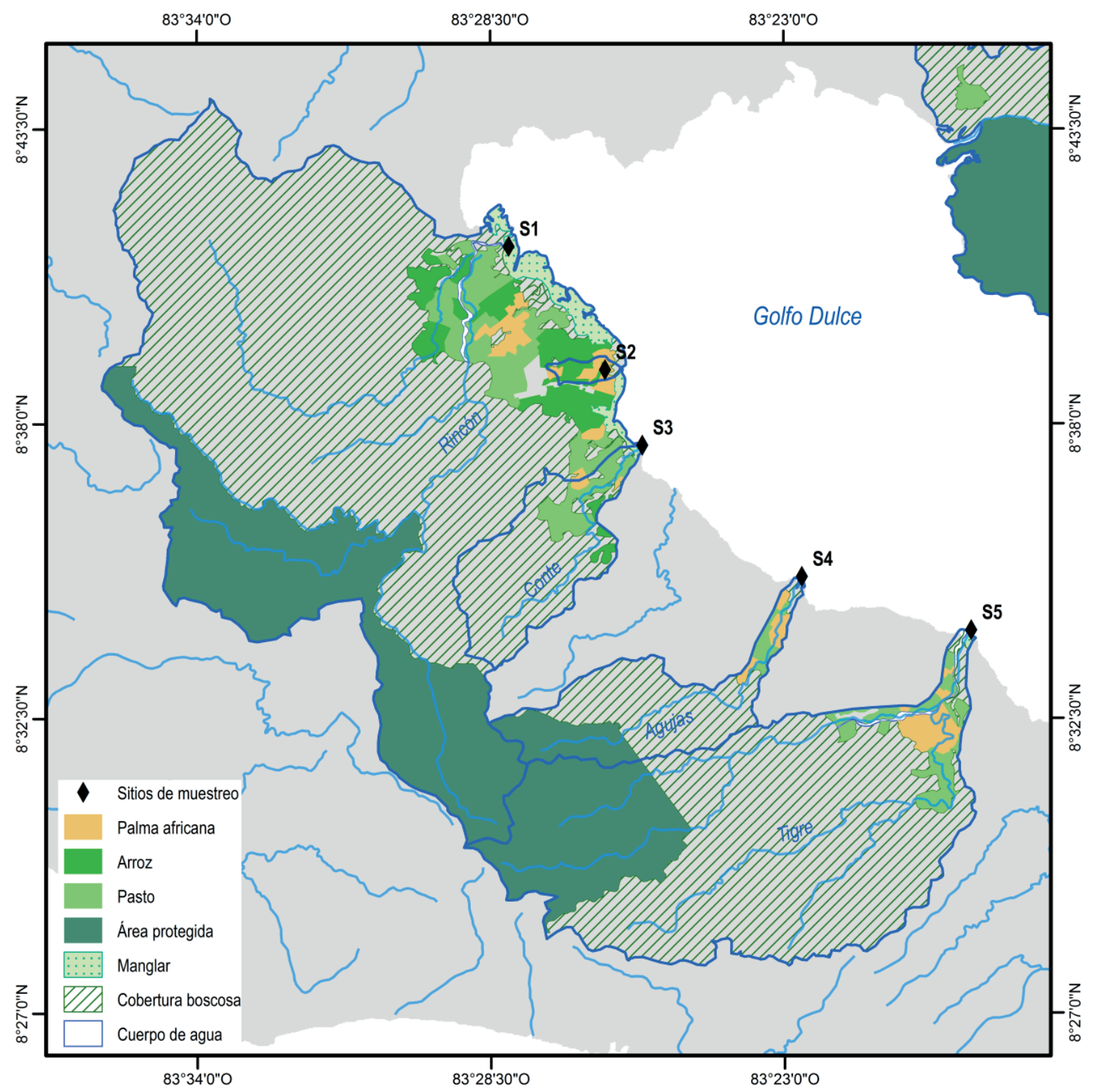

Figura 3. Área de cultivos agrícolas en la margen occidental de Golfo Dulce, 2012.

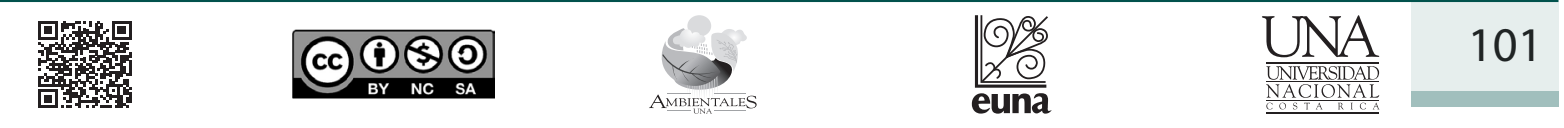




\section{Revista de CIENCIAS AMBIENTALES Tropical Journal of Environmental Sciences}

Revista de Ciencias Ambientales (Trop J Environ Sci). EISSN: 2215-3896.

(Enero-Junio, 2019) . Vol 53(1): 92-112.

Dol: http://dx.doi.org/10.15359/rca.53-1.5

Open Access: www.revistas.una.ac.cr/ambientales

EMAlL: revista.ambientales@una.ac.c Fournier M. L., Castillo L. E., Ramírez F., Moraga G., Ruepert C.

\subsection{Uso de agroquímicos}

Durante el periodo arrocero 2013-2014, en las plantaciones de arroz de secano en la zona del Golfo Dulce se aplicaron en promedio 20.4 kg i.a. ha ${ }^{-1} \mathrm{ano}^{-1}$ en dos ciclos de cultivo (Cuadro 2). Este dato es similar al de zonas arroceras de la península de Nicoya en el Pacífico norte (Bravo et al., 2013) y a datos calculados para río Claro, una zona cercana al área de estudio, también en el cantón de Golfito (bases de datos del IRET sin publicar). Mediante las encuestas se logró identificar el uso de 36 plaguicidas distintos ( 16 herbicidas, 10 fungicidas, 6 insecticidas y 4 bactericidas); 12 i.a. del total son empleados por más de la mitad de los sujetos productores entrevistados. Los campos de arroz en el área de estudio se fertilizaron de 2 a 3 veces por ciclo; se estimó un promedio de $850 \mathrm{~kg}$ de fertilizante químico granulado $(\mathrm{N}-\mathrm{P}-\mathrm{K})$ por hectárea por año. Un tercio del público usuario entrevistado aplica formulaciones comerciales que contienen los antibióticos oxitetraciclina, estreptomicina y kasugamicina.

En el cultivo de palma aceitera, el grupo de los herbicidas es el de mayor uso, 11 de los 14 plaguicidas aplicados (Ramírez et al., 2017). El insecticida carbaril se usa en todas las plantaciones de manera puntual en trampas para control del picudo Rhynchophorus palmarum (coleóptero). Además, Bacillus thuringiensis se aplica vía aérea en áreas muy reducidas y no todos los años, como control biológico en zonas con problemas de insectos defoliadores. Por otro lado, en la etapa de vivero solo se usa el fungicida benomil para el control de patógenos. De acuerdo con Ramírez et al. (2017), en palma se aplica un promedio $6.6 \mathrm{~kg}$ i.a./ha/año y $833 \mathrm{~kg} / \mathrm{ha} / \mathrm{año} \mathrm{de}$ fertilizantes granulados de formulaciones diversas, según los requerimientos del suelo.

Al multiplicar el área total sembrada por cultivo y su uso promedio de agroquímicos (en $\mathrm{kg}$ de i.a/ ha/ año), se calculó la carga total anual de agroquímicos, la cual fue en arroz de $202.5 \mathrm{t}$ de plaguicida y de 8840 t de fertilizante granulado; y en palma aceitera de $210 \mathrm{t}$ de plaguicida y 25450 t de fertilizante granulado. Al arroz se le aplica 3 veces más plaguicida en una relación de área palma/arroz de 3:1 y similar cantidad de abono que a la palma. En ambos cultivos se aplica, con frecuencia de media a alta, los herbicidas glifosato, paraquat y 2,4-D y, en menor cantidad, triclopir; todos estos plaguicidas tienen alta solubilidad y toxicidad moderada para organismos acuáticos (University of Hertfordshire, 2018).

\subsection{Residuos de plaguicidas y otros contaminantes}

Se detectaron plaguicidas en los 8 puntos de muestreo y en el $100 \%$ de las muestras de agua. Cuatro plaguicidas fueron detectados en las muestras de agua: el herbicida clomazone, el insecticida triazofos y los fungicidas isoprotiolano y propiconazol; los cuatro plaguicidas son aplicados en arroz y están presentes en la subcuenca Coto-Colorado (Cuadro 3). El clomazone se detectó en todos los sitios de muestreo. No se hallaron residuos de plaguicidas en las muestras de sedimento, pero sí trazas de pp'-DDE (el metabolito principal de pp'-DDT) en 3 de las 10 especies de peces analizados. Las concentraciones de mercurio total encontradas en los peces (Cuadro 4) están bajo el límite de $0.5 \mu \mathrm{g} / \mathrm{g}$ de peso húmedo, establecido para consumo humano (MAG, 2008).

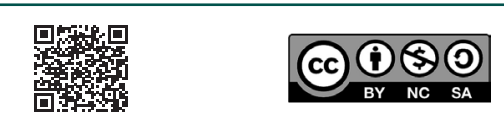

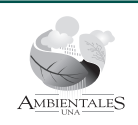

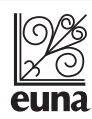




\section{Revista de Desde 1980 CIENCIAS AMBIENTALES Tropical Journal of Environmental Sciences}

Revista de Ciencias Ambientales (Trop J Environ Sci). EISSN: 2215-3896.

(Enero-Junio, 2019) . Vol 53(1): 92-112. Dol: http://dx.doi.org/10.15359/rca.53-1.5

Open Access: www.revistas.una.ac.cr/ambientales

EMAlL: revista.ambientales@una.ac.c Fournier M. L., Castillo L. E., Ramírez F., Moraga G., Ruepert C.

Cuadro 2. Plaguicidas usados en cultivos de arroz y palma aceitera en la cuenca de Golfo Dulce

\begin{tabular}{|c|c|c|c|c|}
\hline \multirow[t]{2}{*}{ Plaguicida (i.a.) - acción biocida ${ }^{*}$} & \multicolumn{2}{|c|}{$\begin{array}{l}\text { Promedio de uso } \\
\left(\mathrm{kg} \text { i.a. } \text { ha }^{-1} \text { año }^{-1}\right)\end{array}$} & \multicolumn{2}{|c|}{$\begin{array}{l}\text { Porcentaje de usuarios } \\
\left(\mathbf{a n ̃ o n}^{-1}\right)\end{array}$} \\
\hline & arroz & palma & arroz & palma \\
\hline ácido oxolínico - B & 0.08 & & 14 & \\
\hline aminopyralid - H & 0.02 & & 14 & \\
\hline Bacillus thuringiensis (BT) -I & & 0.09 & & 13 \\
\hline benomil - F & & 0.09 & & 13 \\
\hline bentazon- $\mathrm{H}$ & 0.10 & & 14 & \\
\hline bispiribac sodio - $\mathrm{H}$ & 0.08 & & 57 & \\
\hline butaclor - $\mathrm{H}$ & 2.10 & & 29 & \\
\hline captan - F & 0.20 & & 29 & \\
\hline carbaril - I & & 0.08 & & 100 \\
\hline carbendazina - F & 1.78 & & 100 & \\
\hline carboxin - F & 0.20 & & 29 & \\
\hline cipermetrina - I & 0.20 & & 57 & \\
\hline clomazone-H & 0.04 & & 14 & \\
\hline diazinon - I & 0.08 & & 14 & \\
\hline dimetoato - I & 0.32 & & 43 & \\
\hline diuron - $\mathrm{H}$ & & 0.12 & & 50 \\
\hline estreptomicina $-\mathrm{B}$ & 0.02 & & 29 & \\
\hline fluazifop - H & & 0.03 & & 25 \\
\hline glifosato - H & 2.16 & 4.27 & 86 & 88 \\
\hline glufosinato de amonio - $\mathrm{H}$ & & 0.006 & & 13 \\
\hline haloxifop - H & & 0.09 & & 88 \\
\hline imidacloprid - I & 0.48 & & 43 & \\
\hline isoprotiolano - F & 0.44 & & 14 & \\
\hline kasugamicina - B & 0.004 & & 29 & \\
\hline lambda cihalotrina - I & 0.002 & & 29 & \\
\hline mancozeb - F & 4.36 & & 71 & \\
\hline MCPA - H & 0.20 & & 57 & \\
\hline metil tiofanato - F & 0.80 & & 14 & \\
\hline metsulfuron - H & & 0.003 & & 25 \\
\hline MSMA - H & & 0.01 & & 50 \\
\hline oxicloruro de cobre - F & 0.14 & & 57 & \\
\hline oxifluorfen - $\mathrm{H}$ & & 0.02 & & 13 \\
\hline oxitetraciclina - B & 0.002 & & 29 & \\
\hline paraquat - $\mathrm{H}$ & 1.6 & 1.04 & 43 & 38 \\
\hline pendimetalina $-\mathrm{H}$ & 1.42 & & 43 & \\
\hline permetrina - I & 0.08 & & 29 & \\
\hline piperofos - H & 0.18 & & 57 & \\
\hline pirazosulfuron etil - $\mathrm{H}$ & 0.02 & & 29 & \\
\hline profoxidim - $\mathrm{H}$ & 0.16 & & 29 & \\
\hline propanil- H & 2.66 & & 71 & \\
\hline propiconazol -F & 0.18 & & 57 & \\
\hline quinclorac - H & 0.12 & & 14 & \\
\hline tebuconazole - F & 0.16 & & 57 & \\
\hline triadimenol - F & 0.04 & & 43 & \\
\hline triclopir -H & 0.08 & 0.39 & 43 & 25 \\
\hline $2,4-\mathrm{D}-\mathrm{H}$ & 0.44 & 0.40 & 71 & 50 \\
\hline Total anual & 20.4 & 6.6 & & \\
\hline
\end{tabular}

Fuente: Ramírez et al. (2017), para palma aceitera y encuestas realizas para arroz.

*Acción biocida: $\mathrm{H}$ herbicida, I insecticida, $\mathrm{F}$ fungicida, B bactericida.

(cc)

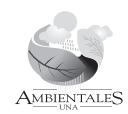



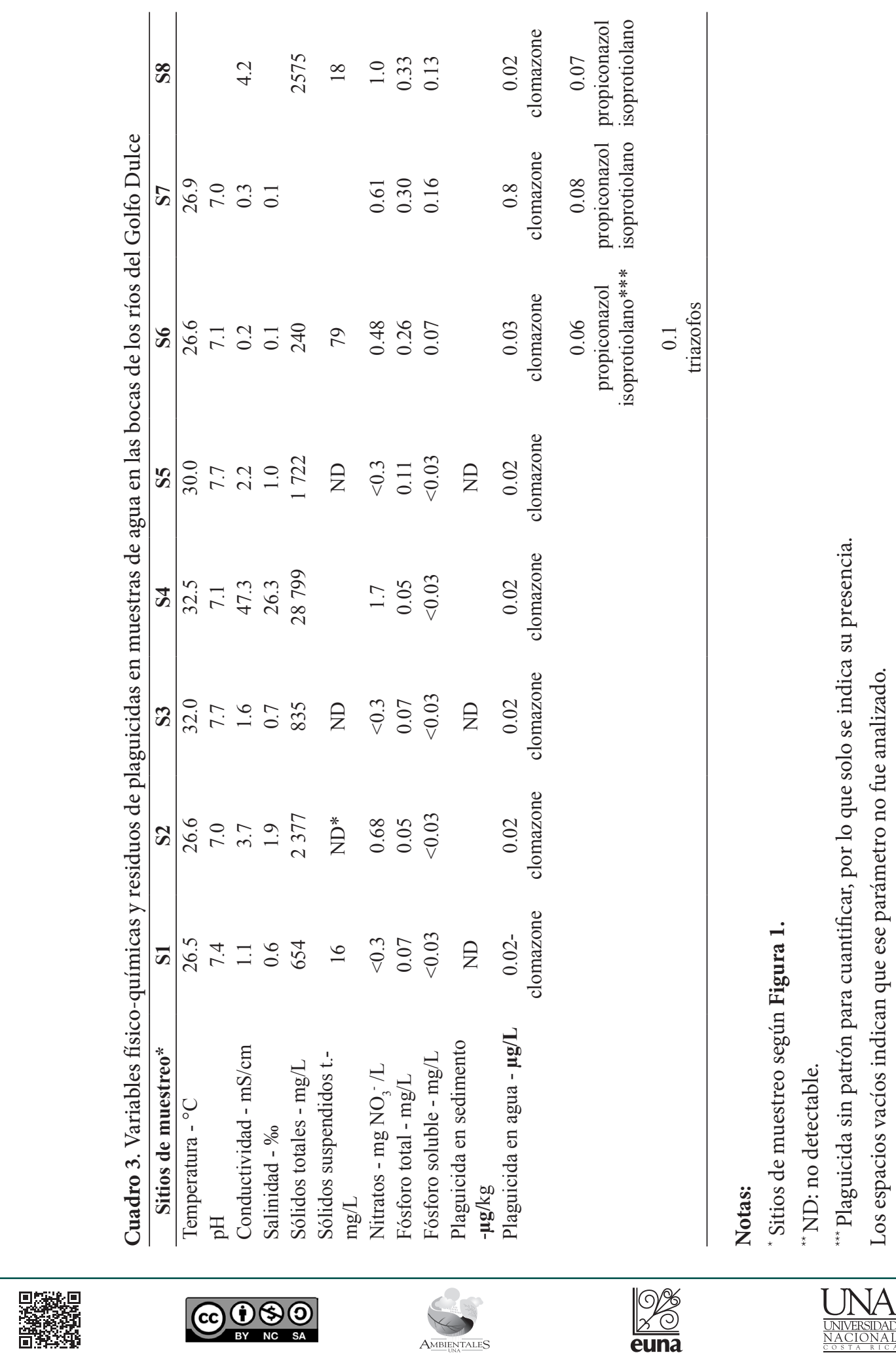


\section{Revista de Desde
Since 1980 CIENCIAS AMBIENTALES Tropical Journal of Environmental Sciences}

Revista de Ciencias Ambientales (Trop J Environ Sci). EISSN: 2215-3896. (Enero-Junio, 2019) . Vol 53(1): 92-112. Dol: http://dx.doi.org/10.15359/rca.53-1.5 Open Access: www.revistas.una.ac.cr/ambientales EMAlL: revista.ambientales@una.ac.c Fournier M. L., Castillo L. E., Ramírez F., Moraga G., Ruepert C.

Cuadro 4. Residuos de plaguicidas y mercurio (Hg-T) en muestras de peces de las bocas de los ríos del Golfo Dulce

\begin{tabular}{|c|c|c|c|c|c|}
\hline Especie $^{*}$ (Familia) & Nombre vernáculo & $\begin{array}{l}\text { Largo están- } \\
\text { dar }(\mathbf{c m})\end{array}$ & Peso total (g) & Plaguicidas & $\begin{array}{c}\text { Hg-T } \\
\text { (ng/g peso } \\
\text { húmedo)*** }\end{array}$ \\
\hline $\begin{array}{l}\text { Hemiramphus saltator } \\
\text { Gilbert y Starks, } 1904 \\
\text { (Hemiramphidae) }\end{array}$ & $\begin{array}{l}\text { Aguja, medio pico, } \\
\text { pajarito }\end{array}$ & 22.9 & 54.2 & & 43.6 \\
\hline $\begin{array}{l}\text { Centropomus nigrescens } \\
\text { Gunther, } 1864 \\
\text { (Centropomidae) }\end{array}$ & Róbalo negro, róbalo & 33.0 & 778.1 & & 140.4 \\
\hline $\begin{array}{l}\text { Oligoplites altus } \\
\text { Günther, } 1868 \\
\text { (Carangidae) }\end{array}$ & $\begin{array}{l}\text { Sierra, cuero, palo- } \\
\text { meta }\end{array}$ & 30.5 & 412.8 & $\begin{array}{c}* * \text { trazas de } \\
\text { pp'-DDE }\end{array}$ & 326.6 \\
\hline $\begin{array}{l}\text { Caranx caninus } \\
\text { Günther, } 1867 \\
\text { (Carangidae) }\end{array}$ & Jurel, toro & 30.0 & 770.1 & $\begin{array}{c}* * \text { trazas de } \\
\text { pp'-DDE }\end{array}$ & 122.5 \\
\hline $\begin{array}{l}\text { Cynoscion squamipinnis } \\
\text { Günther, } 1867 \\
\text { (Sciaenidae) }\end{array}$ & Corvina aguada & 30.0 & 490.1 & $\begin{array}{c}* * \text { trazas de } \\
\text { pp'-DDE }\end{array}$ & 61.7 \\
\hline (Aridae) & Cuminate & 25.0 & 240.2 & & 96.8 \\
\hline $\begin{array}{l}\text { Pomadasys macracan- } \\
\text { thus Günther, } 1864 \\
\text { (Haemulidae) }\end{array}$ & Roncador, ronco & 20.5 & 234.3 & & 64.8 \\
\hline $\begin{array}{l}\text { Balistes polylepis } \\
\text { Steindachner, } 1876 \\
\text { (Balistidae) }\end{array}$ & Chancho & 27.0 & 742 & & 75.7 \\
\hline $\begin{array}{l}\text { Eucinostomus sp. } \\
\text { (Gerreidae) }\end{array}$ & $\begin{array}{c}\text { Palmito, blanquito, } \\
\text { chubeco }\end{array}$ & 13.0 & 55.2 & & 61.8 \\
\hline $\begin{array}{l}\text { Lutjanus guttatus } \\
\text { Steindachner, } 1869 \\
\text { (Lutjanidae) }\end{array}$ & $\begin{array}{c}\text { Pargo de la mancha, } \\
\text { pargo manchado }\end{array}$ & 13.9 & 66.7 & & 25.8 \\
\hline
\end{tabular}

* No se indica el punto de recolección dada la movilidad de las especies

${ }^{\star *}$ Trazas: entre límites de detección $(0.1 \mu \mathrm{g} / \mathrm{g})$ y de cuantificación $(0.5 \mu \mathrm{g} / \mathrm{g})$

*** Límites para consumo: 500 ng/g de peso húmedo (MAG, 2008)

(cc)

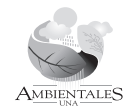




\section{Revista de CIENCIAS AMBIENTALES Tropical Journal of Environmental Sciences}

Revista de Ciencias Ambientales (Trop J Environ Sci). EISSN: 2215-3896.

(Enero-Junio, 2019) . Vol 53(1): 92-112.

Dol: http://dx.doi.org/10.15359/rca.53-1.5

Open Access: www.revistas.una.ac.cr/ambientales

EMAlL: revista.ambientales@una.ac.c

Fournier M. L., Castillo L. E., Ramírez F., Moraga G., Ruepert C.

\section{Discusión}

La agricultura de arroz y palma aceitera ocupa un $20 \%$ (40 685 ha) del área total estudiada en la cuenca del Golfo Dulce; no obstante, el $62 \%$ (135 000 ha) de la cuenca se encuentra cubierta por bosques, de los cuales solo 26000 ha tienen alguna categoría de manejo. La mayoría de las plantaciones están en Coto Colorado (39 000 ha), en donde cerca de 2100 ha de manglar contribuyen a amortiguar los impactos antropogénicos hacia el estuario. Los procesos de circulación y sedimentación en el manglar retardan el arrastre directo de residuos de plaguicidas al mar y permiten un mayor tiempo para su degradación (Ewel et al., 1998). En el sector de la península de Osa, la superficie de cultivo es reducida (2 $560 \mathrm{ha}$ ) y los parches de manglar son mínimos, exceptuando la desembocadura del río Rincón con 480 ha de manglar. Además, como se siembra en la planicie costera, el escurrimiento de plaguicidas hacia el estuario se podría dar en un periodo corto de tiempo, potenciado por una alta precipitación anual de $4500 \mathrm{~mm}$ (Solano y Villalobos, 2001).

En solo una campaña de muestreo se encontraron residuos del herbicida clomazone, en todos los ríos muestreados. Este plaguicida es utilizado para controlar gramíneas y malezas de hoja ancha en los arrozales, tiene una movilidad moderada en el suelo y es poco probable que contamine aguas subterráneas. No obstante, es altamente soluble en agua, lo que facilita su dispersión hacia los cuerpos de agua superficiales a través de la escorrentía. La toxicidad de un plaguicida se evalúa en el laboratorio mediante pruebas ecotoxicológicas estándar, con especies centinelas de microcrustáceos, peces y algas microscópicas, entre otros. Este herbicida se categorizó con una toxicidad de media a alta en invertebrados de agua dulce y estuarinos (EPA, 2007b). En el cultivo de arroz, se hacen aplicaciones aéreas de plaguicidas, un factor importante de deriva al ambiente (Gil y Sinfortc, 2005); en la zona es común la aplicación de herbicidas, fungicidas e insecticidas con avionetas, varias veces durante el ciclo de cultivo.

Este herbicida también ha sido detectado en muestras de agua y pasto marino, en el sitio de forrajeo de la tortuga verde del Pacífico frente a playa Colibrí, al sur de la desembocadura del río Rincón, en puntos cercanos a arrozales (Sarmento et al., 2015). Lo anterior confirma no solo su ocurrencia, sino la relevancia en el seguimiento de su presencia ambiental y la evaluación del riesgo para la biodiversidad de este ecosistema. En el caso de las tortugas marinas, en esa margen del golfo se han identificado además otras zonas importantes de alimentación de la tortuga carey (especie incluida en la lista de la Convención CITES), durante la época de menor turbidez de las aguas; el incremento de los monocultivos aumentaría la presión sobre esta especie de tortuga amenazada (Chacón-Chaverri et al., 2015).

Otros plaguicidas detectados fueron los fungicidas isoprotiolano y propiconazol, ambos medianamente solubles en agua y de persistencia moderada en suelo, con toxicidad media para organismos acuáticos. Por su parte, el insecticida triazofos, de baja solubilidad, tiene una toxicidad alta para peces, de media a alta para invertebrados acuáticos y moderada para algas (University of Hertfordshire, 2018). Las concentraciones de plaguicidas encontradas en las muestras de agua de este estudio son bajas, pero destaca su presencia en todos los ríos y en una sola

\begin{tabular}{|c|c|c|}
\hline 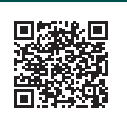 & (c) (i) (5) (2) & 106 \\
\hline
\end{tabular}




\section{Revista de CIENCIAS AMBIENTALES Tropical Journal of Environmental Sciences}

Revista de Ciencias Ambientales (Trop J Environ Sci). EISSN: 2215-3896.

(Enero-Junio, 2019) . Vol 53(1): 92-112.

Dol: http://dx.doi.org/10.15359/rca.53-1.5

Open Access: www.revistas.una.ac.cr/ambientales

EMAIL: revista.ambientales@una.ac.c

Fournier M. L., Castillo L. E., Ramírez F., Moraga G., Ruepert C.

campaña de muestreo. Salvo en el río Agujas, todas las muestras se recolectaron en agua dulce, entre 1.9 y $0.11 \%$ de salinidad. El valor de los sólidos suspendidos totales fue alto en los ríos Rincón, Sábalo y Coto; en este último el valor triplica el límite máximo establecido en el reglamento nacional para evaluar los cuerpos de aguas superficiales: de acuerdo con este, tiene potencial de impactar la comunidad de organismos acuáticos. En cuanto a los nutrientes, también en Coto Colorado, se encontraron concentraciones de fósforo más altas en relación con las otras subcuencas muestreadas.

Estos son de los primeros datos reportados sobre la presencia de residuos de plaguicidas agrícolas de uso actual en los ríos que drenan al Golfo Dulce. En otras investigaciones se ha estudiado la presencia de compuestos orgánicos persistentes (COP), tales como el heptacloro, endosulfan, metabolitos de DDT, dieldrin y endrin en los sedimentos del río Esquinas. Algunos COP fueron detectados en concentraciones cercanas a los límites de detección (Spongberg y Davis, 1998). También se han detectado bifenilos policlorados (PCB) en sedimentos de la región profunda del golfo - 110 y $190 \mathrm{~m}$ - (Spongberg, 2004).

En cuanto a las muestras de peces, se encontraron trazas del metabolito DDE en músculo de corvina, jurel y sierra. Además, las concentraciones de Hg-T analizadas en las 10 especies de peces están bajo los límites establecidos para consumo de $500 \mathrm{ng} / \mathrm{g}$ de peso húmedo (MAG, 2008); los niveles de Hg-T detectados no representan un riesgo para la salud humana. Aun así, al relacionar la concentración de mercurio medida y el peso total del pez, se encontró en el sierra Oligoplites altus un valor más alto con respecto a los otros peces. Esta especie es carnívora y se alimenta de peces óseos y macroinvertebrados (Yáñez-Arancibia, 1978), y es probable que ese valor se relacione con una posición más alta en la cadena trófica. No existen otros estudios con datos sobre la presencia de mercurio en peces del Golfo Dulce.

La información oceanográfica disponible señala el potencial de arrastre y dispersión de residuos de plaguicidas y otras sustancias, a través de los ríos hacia el golfo. Las subcuencas que más agua aportan son Coto Colorado, Esquinas, Rincón y Tigre, con un mínimo en febrero de 20 $\mathrm{m}^{3} / \mathrm{s}$ en Rincón y un máximo en octubre de $180 \mathrm{~m}^{3} / \mathrm{s}$ en Coto Colorado (Svendsen et al., 2006). Los ríos de las subcuencas Esquinas y Coto Colorado contribuyen con el 90 \% del agua que entra al golfo por drenaje continental (Lei, 2002). Durante la estación lluviosa, la pluma en estos ríos se extiende por $250 \mathrm{~km}^{2}$, más de la tercera parte de la superficie del golfo. También en la estación seca la pluma del Coto Colorado influye en la parte externa del golfo y se dispersa desde su desembocadura en dirección oeste-suroeste sobre unos $40 \mathrm{~km}^{2}$; es el río más influyente en la hidrografía del golfo y alcanza a reducir la salinidad en forma considerable en un área mayor a $100 \mathrm{~km}^{2}$ (Rincón y Ballestero, 2015). Las estelas de los ríos de la margen occidental se extienden en superficie hacia la parte interna del golfo (Rincón y Ballestero, 2015), y eventualmente podrían trasladar residuos de sustancias utilizadas en la agricultura.

Como en la mayor parte del país, en los campos de cultivo de la cuenca del Golfo Dulce se implementan pocas prácticas de conservación de suelos y, por el contrario, las márgenes de ríos y quebradas se deforestan. Los bosques riparios son muy importantes, pues mitigan la entrada

\begin{tabular}{|c|c|c|}
\hline 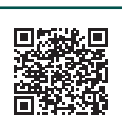 & (c) (1) (8)(2) (2) & 107 \\
\hline
\end{tabular}




\section{Revista de CIENCIAS AMBIENTALES Tropical Journal of Environmental Sciences}

Revista de Ciencias Ambientales (Trop J Environ Sci). ElSSN: 2215-3896.

(Enero-Junio, 2019) . Vol 53(1): 92-112.

Dol: http://dx.doi.org/10.15359/rca.53-1.5

Open Access: www.revistas.una.ac.cr/ambientales

EMAlL: revista.ambientales@una.ac.c

Fournier M. L., Castillo L. E., Ramírez F., Moraga G., Ruepert C.

de sedimentos, nutrientes y residuos de plaguicidas a los ríos y protegen la calidad del agua y la biodiversidad (Dosskey et al., 2010). En otras áreas tropicales del Pacífico occidental, se ha estudiado la pérdida del bosque de ribera causada por el cultivo de palma aceitera y los efectos sobre los cuerpos de agua (Sheaves et al., 2018).

En esta evaluación preliminar de la agricultura en la cuenca del Golfo Dulce, se determinó la extensión de dos monocultivos: arroz y palma aceitera, de uso medio y bajo de plaguicidas respectivamente, en contraposición a otros de alto insumo como banano y piña, sembrados en otras regiones del país (Echeverría-Sáenz et al., 2018). No obstante, se logró detectar, en un único muestreo, residuos en el agua de las desembocaduras de los ríos. Por lo anterior, y considerando la alta pluviosidad en el área, las condiciones oceanográficas y la riqueza biológica del estuario, es importante diseñar, para al menos un ciclo anual, un plan de monitoreo de la calidad del agua en los ríos, aguas abajo de las plantaciones.

En particular, es recomendable evaluar los ríos Coto y Sábalo de la subcuenca Coto Colorado y el río Rincón; analizar residuos de plaguicidas, antibióticos (aplicados en los arrozales), sólidos suspendidos y nutrientes, y evaluar su impacto en la salud del ecosistema. No obstante, en este estudio se detectaron concentraciones bajas de nitratos en todos los sitios, la agricultura es la fuente de contaminación por nitrógeno más importante en los ecosistemas marino costeros del planeta (Howarth, 2008). Es relevante incluir, en futuras investigaciones, ensayos con biomarcadores en peces, para detectar efectos tempranos por contaminación. Con la finalidad de mitigar la contaminación difusa hacia los cuerpos de agua generada por la agricultura, es fundamental la creación de programas para la restauración de los bosques de ribera -dentro del marco de la legislación forestal vigente-, con participación de las comunidades, centros docentes, personas propietarias de parcelas agrícolas y gobierno.

\section{Conclusiones}

El Golfo Dulce es un sitio relevante para la protección marina y es uno de los vacíos de conservación identificados en el país. Los resultados de esta evaluación preliminar indican un desarrollo agrícola de importancia para los cultivos de palma aceitera y de arroz en la cuenca del golfo. Una quinta parte de la cuenca es actualmente usada en agricultura, pero existe una cobertura forestal significativa en casi toda la cuenca, así como de manglar en las subcuencas Coto Colorado y Rincón. El uso de agroquímicos y la presencia de plaguicidas en las muestras puntuales de agua podrían indicar un riesgo de escorrentía de plaguicidas y otros contaminantes al golfo, por eso sobresale la necesidad de estudios futuros. Dada la extensión y el manejo de las plantaciones agrícolas en la cuenca del Golfo Dulce, es recomendable desarrollar medidas de mitigación, para reducir posibles efectos negativos sobre los recursos del estuario.

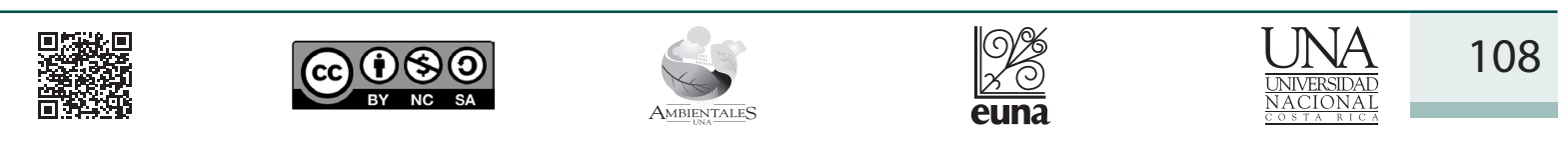




\section{Revista de CIENCIAS AMBIENTALES Tropical Journal of Environmental Sciences}

Revista de Ciencias Ambientales (Trop J Environ Sci). EISSN: 2215-3896. (Enero-Junio, 2019) . Vol 53(1): 92-112. Dol: http://dx.doi.org/10.15359/rca.53-1.5 Open Access: www.revistas.una.ac.cr/ambientales EMAlL: revista.ambientales@una.ac.cr Fournier M. L., Castillo L. E., Ramírez F., Moraga G., Ruepert C.

\section{Agradecimientos}

El equipo investigador agradece a la Federación Costarricense de Pesca Turística (FECOP) por el aporte de fondos de cooperación para la ejecución de este estudio. Así mismo, al Programa de Investigaciones Aerotransportadas y Sensores Remotos e in situ (PRIAS) del Centro Nacional de Alta Tecnología (CeNAT) y al Consejo Nacional de Rectores (CONARE), por facilitar el uso de imágenes satelitales. Por su apoyo en el análisis de mercurio, al Dr. Feiyue Wang de la Universidad de Manitoba, Canadá. A Raúl Rojas Figueroa de la Universidad de Costa Rica y a Margaret Pinnock del IRET- UNA, por la identificación taxonómica, y las mediciones y disección de los peces, respectivamente. Por último, a la Revista y a las personas revisoras anónimas por sus observaciones y comentarios a la versión final del manuscrito.

\section{Referencias}

American Public Health Association [APHA]. (2005) Standard Methods for the Examination of Water and Wastewater. Washington DC: APHA.

Araya-Alpízar, C. y Galindo-Villardon, M. P. (2009). Tamaño de la muestra en investigación clínica. Medicina Clínica, 133(1), 26-30. https://doi.org/10.1016/j.medcli.2008.10.048

Beketov, M. A., Kefford, B. J., Schäfer, R. B., \& Liess, M. (2013). Pesticides reduce regional biodiversity of stream invertebrates. Proceedings of the National Academy of Sciences of USA, 110(27), 11039-11043. https://doi.org/10.1073/pnas.1305618110

Bravo, V., de la Cruz, E., Herrera, G., y Ramírez, F. (2013). Uso de plaguicidas en cultivos agrícolas como herramienta para el monitoreo de peligros en salud. Uniciencia, 27(1), 351-376.

Chacón-Chaverri, D., Martínez-Cascante, D., Rojas, D. y Fonseca, L.G. (2015). Golfo Dulce, Costa Rica, un área importante de alimentación para la tortuga carey del Pacífico Oriental (Eretmochelys imbricata). Revista Biología Tropical, 63(1), 351-362.

Cortés, J. (1992). Los arrecifes coralinos de Golfo Dulce, Costa Rica: Aspectos ecológicos. Revista Biología Tropical, 40(1), 19-26.

Dosskey, M. G., Vidon, P., Gurwick, N. P., Allan, C. J., Duval, T. P., \& Lowrance, R. (2010). The Role of Riparian Vegetation in Protecting and Improving Chemical Water Quality in Streams. Journal of the American Water Resources Association, 42(2), 261-277. https://doi. org/10.1111/j.1752-1688.2010.00419.x

Echeverría-Sáenz, S., Mena, F., Pinnock, M., Ruepert, C., Solano, K., de la Cruz, E., Campos, B., Sánchez-Ávila, J., Lacorte, S., \& Barata C. (2012) Environmental hazards of pesticides from pineapple crop production in the Río Jiménez watershed (Caribbean Coast, Costa Rica). Science of the Total Environment, 440, 106-114. https://doi.org/10.1016/j.scitotenv.2012.07.092

\begin{tabular}{|c|c|c|}
\hline 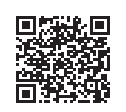 & (c) (1) (5) () & 109 \\
\hline
\end{tabular}




\section{Revista de CIENCIAS AMBIENTALES Tropical Journal of Environmental Sciences}

Revista de Ciencias Ambientales (Trop J Environ Sci). EISSN: 2215-3896. (Enero-Junio, 2019) . Vol 53(1): 92-112. D0l: http://dx.doi.org/10.15359/rca.53-1.5 Open Access: www.revistas.una.ac.cr/ambientales EMAlL: revista.ambientales@una.ac.c Fournier M. L., Castillo L. E., Ramírez F., Moraga G., Ruepert C.

Echeverría-Sáenz, S., Mena, F., Arias-Andrés, M., Vargas, S., Ruepert, C., Van den Brink, P., Castillo, L.E. \& Gunnarsson, P.S. (2018) In situ toxicity and ecological risk assessment of agro-pesticide runoff in the Madre de Dios River in Costa Rica. Environmental Science and Pollution Research, 25, 13270-13282. https://doi.org/10.1007/s11356-016-7817-4

Environmental Protection Agency [EPA]. (2007a). Method 3546 Microwave extraction. Test Methods for Evaluating Solid Waste: Physical/Chemical Methods. SW 846. Recuperado de https://19january2017snapshot.epa.gov/sites/production/files/2015-2/documents/3546.pdf

Environmental Protection Agency [EPA]. (2007b). Clomazone Summary Document: Registration Review. Recuperado de https://archive.epa.gov/oppsrrd1/registration_review/web/pdf/ clomazone_summary.pdf.

Ewel, K. C., Twilley, R. R \& Ong, J. E. (1998). Different kinds of mangrove forests provide different goods and services. Global Ecology \& Biogeography Letters, 7, 83-94. https:// doi.org/10.2307/2997700

Fournier, M. L., Echeverría-Sáenz, S., Mena, F., Arias-Andrés, de la Cruz E., Ruepert, C. (2018). Risk assessment of agriculture impact on the Frío River watershed and Caño Negro Ramsar wetland, Costa Rica. Environmental Science Pollution Research, 25, 13347-13359. https://doi. org/10.1007/s11356-018-1887-4

Gil, Y. \& Sinfortc, C. (2005). Emission of pesticides to the air during sprayer application: A bibliographic review. Atmospheric Environment, 39(28), 5183-5193. https://doi.org/10.1016/j. atmosenv.2005.05.019

Howarth, R. (2008). Coastal nitrogen pollution: A review of sources and trends globally and regionally. Harmful Algae, 8, 14-20. https://doi.org/10.1016/j.hal.2008.08.015

Lei, Z. (2002). A Marine and coastal dynamics and primary production response in Golfo Dulce, Costa Rica. A multi-sensor satellite approach (Tesis de maestría). International Institute of Geoinformation and Earth Observation, The Netherlands.

Lindgren, D. T. (1985). Fundamentals of photointerpretation. In Land use planning and remote sensing. Remote Sensing of Earth Resources and Environment (vol. 2). Dordrecht, Holland: Springer. https://doi.org/10.1007/978-94-017-2035-9_4

Mena, F., Fernández, M., Campos, B., Sánchez-Ávila, J., Faria, M., Pinnock, M., de la Cruz, E., Lacorte. S., \& Barata, C. (2014). Pesticide residue analyses and biomarker responses of native Costa Rican fish of the Poeciliidae and Cichlidae families to assess environmental impacts of pesticides in Palo Verde National Park. Environmental Biology, 35, 19-27.

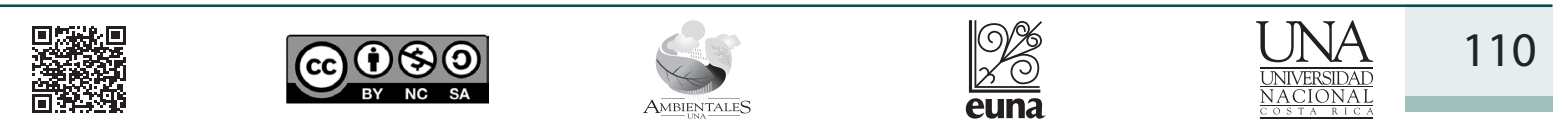




\section{Revista de CIENCIAS AMBIENTALES Tropical Journal of Environmental Sciences}

Revista de Ciencias Ambientales (Trop J Environ Sci). EISSN: 2215-3896. (Enero-Junio, 2019) . Vol 53(1): 92-112. Dol: http://dx.doi.org/10.15359/rca.53-1.5 Open Access: www.revistas.una.ac.cr/ambientales EMAlL: revista.ambientales@una.ac.c Fournier M. L., Castillo L. E., Ramírez F., Moraga G., Ruepert C.

Ministerio de Agricultura y Ganadería [MAG] (2008). Decreto N. ${ }^{\circ}$ 34687. Reglamento de Límites Máximos Microbiológicos y de Residuos de Medicamentos y Contaminantes para los Productos y Subproductos de la Pesca y de Acuicultura Destinados al Consumo Humano. La Gaceta, San José, Costa Rica.

Morales-Ramírez, A. (2011). La diversidad marina del Golfo Dulce, Pacífico Sur de Costa Rica: Amenazas a su conservación. Biocenosis, 24(1-2), 9-20.

Moss, B. (2008). Water pollution by agriculture. Philosophical Transactions of the Royal Society, 363, 659-666. https://doi.org/10.1098/rstb.2007.2176

Ramírez, F., Bravo, V. y de la Cruz, E. (2014). Importación de plaguicidas en Costa Rica: Periodo 1980-2012. Informe interno, Área de Diagnóstico. Heredia, Costa Rica: IRET-UNA.

Ramírez-Muñoz, F., Bravo-Durán, V., y Herrera-Ledezma, G. (2017). Uso del herbicida glifosato en Costa Rica en el periodo 2007 a 2015. Uniciencia, 31(1), 59-72. https://doi.org/10.15359/ ru.31-1.7

Rincón-Alejos, F. y Ballestero-Sakson, D. (2015). Hidrografía y plumas estuarinas en Golfo Dulce, Pacífico Sur de Costa Rica. Revista Biología Tropical, 63(2), 161-181.

Sarmento, M., Chaves, A., Retamosa, M., Ruepert, C., Jiménez, R., y Blanco, K. (2015). Análisis descriptivo de las condiciones de conservación de un sitio de forrajeo de la tortuga verde del Pacífico (Chelonia mydas agassizii, Testudines: Chelonioidea) en el Golfo Dulce, Costa Rica; se toma como base el estado de salud de la tortuga y el hallazgo de plaguicidas en el ambiente. Rev. Ciencias Veterinarias, 33(2), 81-96. https://doi.org/10.15359/rcv.33-2.3

Sheaves, M., Johnston, R., Millera, K., \& Nelson, P.N. (2018). Impact of oil palm development on the integrity of riparian vegetation of a tropical coastal landscape. Agriculture, Ecosystems and Environment, 262, 1-10. https://doi.org/10.1016/j.agee.2018.04.011

Sistema Nacional de Áreas de Conservación [SINAC]. (2008). Mapa de áreas silvestres protegidas, escala 1:50 000 en formato shape de ESRI. Atlas de Costa Rica. San José, Costa Rica.

Smedes, F. (1999). Determination of total lipid using non-chlorinated solvents. Analyst, 124(11):1711-1718. https://doi.org/10.1039/A905904K

Solano, J. y Villalobos, R. (2001). Aspectos fisiográficos aplicados a un bosquejo de regionalización geográfica climática de Costa Rica. Tópicos Meteorológicos, 8(1), 26-39.

Spongberg, A. L. \& Davis, P. (1998). Organochlorinated pesticide contaminants in Golfo Dulce, Costa Rica. Revista Biología Tropical, 46, 111-124. https://doi.org/10.15517/rbt.v46i6.29650

Spongberg, A. L. (2004). PCB Contaminations in marine sediments from Golfo Dulce, Pacific coast of Costa Rica. Revista Biología. Tropical, 52(2), 23-32.

\begin{tabular}{|c|c|c|}
\hline 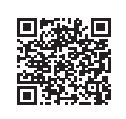 & (c) (i) (5) (2) & 111 \\
\hline
\end{tabular}




\section{Revista de CIENCIAS AMBIENTALES Tropical Journal of Environmental Sciences}

Revista de Ciencias Ambientales (Trop J Environ Sci). EISSN: 2215-3896.

(Enero-Junio, 2019) . Vol 53(1): 92-112. D0l: http://dx.doi.org/10.15359/rca.53-1.5 Open Access: www.revistas.una.ac.cr/ambientales EMAIL: revista.ambientales@una.ac.cr Fournier M. L., Castillo L. E., Ramírez F., Moraga G., Ruepert C.

Svendsen, H., Rosland, R., Myking, S., Vargas, J. A., Lizano, O. G., \& Alfaro, E. J. (2006). A physical-oceanographic study of Golfo Dulce, Costa Rica. Revista Biología Tropical, 54(1), 147 170. https://doi.org/10.15517/rbt.v54i1.26848

University of Hertfordshire. (2018). PPDB: Pesticide Properties DataBase. Recuperado de http:// sitem.herts.ac.uk/aeru/footprint/es/Reports/408.htm\#2

Wolff, M., Hartmann H. J., Koch V. (1996). A pilot trophic model for Golfo Dulce, a fjord-like tropical embayment, Costa Rica. Revista Biología Tropical, 44(3), 215-231.

Yáñez-Arancibia, A. (1978). Taxonomía, ecología y estructura de las comunidades de peces en lagunas costeras con bocas efímeras del Pacífico de México. México D.F. México: Centro de Ciencias del Mar y Limnología-UNAM. 